\section{Pesquisa-ação no estágio supervisionado: contribuições \\ Pesquisa-ação no estágio supervisionado: contribuições
para o ensino de geografia}

Sueli Almeida dos Santos*

Vicente Eudes Lemos

Alves $^{* *}$

Resumo: Pretende-se analisar de maneira sucinta uma experiência no ensino de geografia. Visa-se discutir como foi desenvolvido o trabalho proposto no projeto de estágio e suas diversas etapas realizadas dentro da sala de aula, explicitando as atividades práticas aplicadas para um melhor entendimento dos alunos em relação aos temas trabalhados em aulas expositivas, especialmente a temática da industrialização brasileira, concentração industrial e as migrações internas. Através de uma reflexão sobre os recursos utilizados no ensino da geografia, buscou-se encadear a experiência em sala de aula com o processo de ensino-aprendizagem para justificar a defesa de um planejamento visando associar o ensino de geografia e as representações sociais dos alunos.

\section{Action research in the supervised apprenticeship: contribu- tions to geography teaching}

\begin{abstract}
This work intend to analyze briefly an experience in teaching geography, seeing the idea of the school-based apprenticeship as an important phase in teachers' education. The aim is to discuss how the word proposed in the apprenticeship project and its various steps undertaken within the classroom were developed, explaining the practical activities applied to a better understanding of students concerning the themes discussed in lectures, especially the theme of Brazilian industrialization, industrial concentration and internal migrations. Through a reflection on the resources used in the teaching of geography, we sought to gather the experience in the classroom with the teaching-learning process to justify the defense of a planning aimed at teaching geography through the students' social representations.
\end{abstract}

* Instituto de Geociências, Departamento de Gegrafia, Laboratório de Investigações Geográficas e Planejamento Territorial - GEOPLAN

\section{Palavras-chave: \\ Ensino de geografia, In- dustrialização brasileira, Migração e Representa- ções sociais.}

Key-Words:

Geography education; Industrialization; Migration; Social representations. 


\section{Introdução}

O presente artigo busca apresentar os resultados da experiência no ensino de geografia realizada na $6^{\text {a }}$ série do ensino fundamental numa escola da rede pública do município de Campinas/SP, como atividade prática da disciplina: Estágio Supervisionado de Geografia II, do curso de licenciatura em geografia da Universidade Estadual de Campinas (UNICAMP).

O tema das aulas proposto no projeto de estágio "concentração industrial no Brasil e os fluxos migratórios internos" foi escolhido porque consta nos conteúdos sugeridos na proposta curricular de ensino do estado de São Paulo e nos livros didáticos da $6^{a}$ série. Nestes últimos, porém, trata-se de um conteúdo que aparece frequentemente em capítulos separados. Dessa forma, buscou-se trabalhar de maneira integrada os temas de dois capitulos para que os alunos pudessem compreender melhor a relação entre esses processos, às vezes aparecendo nos livros didáticos como sendo questões desconexas, fato que dificulta a compreensão dos educandos sobre a realidade por eles vivida.

Assim, esse trabalho se divide em três partes, conforme a abordagem apresentada aos alunos em sala de aula e que a reproduzimos nesse texto como tentativa de compreensão do percurso realizado: a primeira composta por uma periodização e discussão dos processos de concentração industrial no Brasil e a sua relação com os fluxos migratórios internos. Analisa-se, em seguida, mesmo que de maneira resumida, o período da instalação das primeiras indústrias no país após o ciclo da economia cafeeira, surgidas do processo de substituição das importações, sendo este o primeiro momento de impulso da industrialização brasileira. Tal fenômeno teve desdobramento quando, numa segunda fase, houve o processo de intensificação da produção industrial, a formação de um mercado nacional e a integração do território brasileiro a partir de uma importante participação das políticas estatais. Destaca-se aqui como o processo de industrialização se concentrou em determinados lugares do país, os quais passaram a receber um grande contingente populacional. Por último, esboça-se uma análise de como essa concentração industrial levou ao congestionamento das regiões mais industrializadas e, consequentemente, a saída de muitas indústrias para outros lugares, além do desencadeamento de mudanças ocorridas na dinâmica populacional.

Na segunda parte do texto explicita-se como ocorreu o trabalho desenvolvido em sala de aula, com os alunos de sexta série do ensino regular, sendo dividida em dois tópicos: no primeiro apresenta-se uma análise das aulas expositivas e, no segundo, das atividades práticas, destacando-se os recursos utilizados nas aulas de geografia e como a partir de uma microescala, que é a sala de aula, foi possível perceber algumas características da dinâmica populacional brasileira com os históricos familiares dos alunos, levantados através de questionários aplicados ao conjunto de 35 educandos. Por fim, as considerações finais sobre o trabalho realizado e como essa experiência pode ser enriquecedora para a formação docente.

\section{Introdução da temática em sala de aula: concentração industrial no país e os fluxos migratórios internos}

$\mathrm{Na}$ abordagem desenvolvida com os alunos destacou-se que a gênese da industrialização no Brasil historicamente esteve vinculada a uma concentração espacial na região Sudeste e esse processo esteve aliado à dinamicidade da cafeicultura no século XIX. Conforme Cano (2007, p. 56), "o café foi, a partir de 1850, a principal atividade econômica do país. Inicialmente implantada no Rio

Geografia Ensino \& Pesquisa, v. 17, n.1 p. $147-160$, jan./abr. 2013

Pesquisa-ação no estágio supervisionado: contribuições para o ensino de Geografia de Janeiro, expandiu-se pelo Vale do Paraíba, abarcando também parte de São Paulo, estendendo-se ainda a Minas Gerais e ao Espírito Santo".

Dentre os estados da região Sudeste, São Paulo foi o que teve maior dinamismo econômico no setor da cafeicultura, favorecendo 0 assentamento de indústrias alimentícias, têxteis e de apoio ao setor agroexportador. Com a crise mundial de 1929, parte do capital cafeeiro foi reinvestida em atividades industriais, pois conforme aponta Cano (2007, p. 39), 
Durante a década de 1920, a economia paulista acentuou a concentração e a modernização da indústria produtora de bens-salário. A partir daí, e mais precisamente após a "Crise de 1929", lançou a semente da futura indústria produtora de bens de produção, que se consolidaria durante a década de 1950. A amplitude de seu próprio mercado proporcionou-lhe atração e posterior concentração da indústria de bens de consumo durável e de capital. Quando isso se dá, a economia paulista já havia consolidado seu predomínio na dinâmica de acumulação à escala nacional. É a partir desse momento que se consolidaria a integração do mercado nacional.

O estado de São Paulo através desse impulso de industrialização ganhou, ao longo do tempo, um diferencial em relação às outras unidades federativas devido à presença de um grande número de indústrias. Nessa primeira fase do processo de industrialização brasileiro (1930-1950), além do capital do comércio do café, dentre as principais vantagens que São Paulo reuniu para o desenvolvimento das atividades industriais, estão:

- Mão de obra assalariada imigrante;

- Ferrovias que ligavam o interior ao porto de Santos;

- O mercado consumidor que se formou na capital paulista e seus arredores.

Com a Segunda Guerra Mundial (1939-1945) e a redução na importação de produtos industrializados em função da dificuldade em comercializar com a Europa, o Brasil visando à substituição das importações, buscou através da produção industrial interna atender as necessidades do mercado nacional. Com isso, aumentou a demanda por mão de obra nas cidades, o que favoreceu a migração interna rural-urbana, uma vez que o fluxo de imigrantes estrangeiros, principal força de trabalho no Brasil no período cafeeiro, havia sofrido forte redução.

A partir de meados do século XX, ocorre o processo de intensificação da indústria, formação de um mercado nacional e integração do território. A instalação de grandes indústrias, especialmente estrangeira, a partir desse período, contribuiu fortemente para a ascensão da industrialização brasileira e foi possivvel graças à infraestrutura implantada pelo Estado nacional, processo este que se iniciou, de maneira mais consolidada, no governo de Getúlio Vargas. Entre os exemplos dos sistemas de engenharia que passam a ser implementados no território brasileiro a partir desse período estão: a Companhia Siderúrgica Nacional, a mineradora Companhia Vale do Rio Doce e a Companhia Hidrelétrica do São Francisco.

Com o governo de Juscelino Kubitschek (1956-1960), através de seu Plano de Metas, houve uma maior participação política e intervenção estatal no planejamento econômico do país. Em tal governo foram priorizadas as obras de transportes (principalmente a construção de rodovias), de comunicação e de geração de energia. Das políticas de planejamento que tiveram impacto na dinâmica populacional no governo JK, destaca-se a criação da Superintendência do Desenvolvimento Econômico do Nordeste (SUDENE) e a tentativa de reter a população nessa região, a transferência da capital brasileira do Rio de Janeiro para Brasília (instalada no centro geográfico do país) e a abertura da Rodovia Belém-Brasília. Esta última também favoreceu, juntamente com a capital federal, a ocupação de parte da região Centro-Oeste. No entanto, todo o incentivo industrial no país concentrou-se principalmente na região Sudeste, em função do seu parque industrial já presente desde o começo do século XX, especialmente no eixo Rio-São Paulo. Concomitantemente com a mecanização agrícola, a migração rural-urbana foi fortemente incentivada especialmente em direção às duas maiores metrópoles do país ${ }^{1}$

Com o golpe militar em 1964 e a ideologia política conservadora que se instala no Brasil, foi reforçada a intervenção estatal na modernização do país, sendo assim "o eixo principal da política de desenvolvimento centrou-se na rápida expansão da industrialização e na concomitante modernização da produção agrícola" (MARTINE, 1989, p. 48). Ainda segundo esse autor "benefícios sociais, assim como a redistribuição de renda, foram adiados como parte da decisão de aproveitar um contexto internacional altamente favorável ao rápido crescimento econômico" (MARTINE, 1989, p. 48).
${ }^{1}$ Martine (1995, p. 63), considera que "os investimentos no parque industrial tiveram forte influência sobre o lócus da expansão das atividades econômicas, 0 que serviu para aumentar a hegemonia da região dominada por São Paulo. Ao mesmo tempo, o dinamismo econômico estimulou a mobilidade geográfica, particularmente para as áreas urbanas do Centro-Sul"

Geografia Ensino \& Pesquisa, v. 17, n.1 p. 147-160, jan./abr. 2013

Santos, S. A.; Alves, V. E. L. 
2 Segundo Martine (1995, p. 64) "o modelo de modernização agrícola adotado veio beneficiar, de forma complementar, a concentração da propriedade e do uso da terra. Por um lado, os subsídios incentivaram a mecanização e, consequentemente a redução da necessidade de mão de obra. Por outro lado, incentivou-se a especulação com a propriedade da terra, expulsando pequenos produtores. Desse modo, a concentração da propriedade rural expulsou da terra um grande número de pequenos agricultores, posseiros, proprietários, parceiros e arrendatários. E como essas categorias de produtores eram justamente as que utilizavam mais intensivamente mão de obra, uma parcela significativa da população agrícola acabou sendo 'liberada' ao mesmo tempo". Ainda segundo esse autor, em função das medidas intensivas do governo para a modernização agrícola, cerca de 29 milhões de pessoas saíram do campo para as cidades entre 1960 e 1980, ( MARTINE, 1989, p. 53).

Geografia Ensino \& Pesquisa, v. 17, n.1 p. 147-160, jan./abr. 2013

Pesquisa-ação no estágio supervisionado: contribuições para o ensino de Geografia
De acordo ainda com Martine (1989), as estratégias de desenvolvimento regional adotadas pelos governos militares permitiram o favorecimento do crescimento econômico das demais regiões e a integrá-las ao mercado nacional em expansão, a partir das políticas de combate aos problemas da seca no Nordeste, da transferência de população principalmente dessa região e do Sul do Brasil para a Amazônia com o intuito de ocupá-la. Tais políticas adotadas mostram a preocupação dos governos do regime militar com a redistribuição da população pelo país. No entanto, todas essas tentativas do Estado não tiveram impactos significativos na redução dos fluxos populacionais em direção ao Sudeste. Em contrapartida, a modernização da agricultura, com a substituição do trabalhador rural pelas máquinas agrícolas (fortemente incentivadas pelos governos militares, com a modernização do campo), com a ausência de políticas de apoio ao pequeno produtor como a garantia da sua permanência na propriedade rural e do acesso dele a terra através da reforma agrária $^{2}$. Aliado a isso, tem-se a concentração dos investimentos industriais na região Sudeste, como já destacado anteriormente, que favoreceu a continuação dos fluxos populacionais em direção a essa região, especialmente para o estado de São Paulo. Esta unidade da federação se tornou a principal receptora das novas indústrias, graças ao significativo parque industrial já presente no estado, em especial, na capital paulista. Assim, com a integração do território nacional e a dinamização do mercado consumidor através do rodoviarismo implantado, São Paulo passa a fornecer produtos industrializados para as outras regiões do país, e também a absorver mão de obra e matéria-prima das demais regiões, no caso da primeira, especialmente do Nordeste.

Entre a década de 1950 e 1970, período de consolidação da industrialização brasileira, a região Sudeste tornou-se a maior área de concentração industrial no país, o que acabou atraindo muitas pessoas de outros lugares que se deslocaram em busca de emprego. As duas maiores metrópoles brasileiras (São Paulo e Rio de Janeiro) e depois também outras cidades da região como é o caso de Campinas, foram as que receberam maior contingente populacional, originário de todas as regiões brasileiras, em especial da região Nordeste, como já destacado anteriormente. De acordo com Cano (2007), nesse período houve um aumento dos fluxos de pessoas dentro do país.

\footnotetext{
O fluxo acumulado de migrantes inter-regionais do país, em 1970, equivalia a $12,8 \%$ da população, bem acima, portanto, dos $8,2 \%$ em 1950. Nesse ano, totalizava 4,3 milhões de pessoas, das quais os nordestinos (exclusive os maranhenses) perfaziam 1,1 e os mineiros 1,3 milhão. Em 1970, compreendia 11,9 milhões de pessoas, das quais os nordestinos (exclusive os maranhenses) perfaziam 3,9 e os mineiros, 3,2 milhões. Esse fluxo praticamente triplica, no mesmo período em que se dá o maior avanço na industrialização brasileira e em que a agricultura acelera seu crescimento e incorpora mais progresso técnico (CANO, 2007, p. 288).
}

Segundo Damiani (1991, p. 57), com o processo de industrialização acelerada e a acumulação capitalista, a população tende a se concentrar nas cidades, nascendo, nesse contexto, as regiões metropolitanas. Por isso, há necessidade de um estudo geográfico da população a partir de grupos mais homogêneos, como a população urbana e a rural, tipos de profissões, etc.. "As particularidades históricas deveriam, então, adequar-se a uma estrutura de análise que fixaria certos elementos básicos de medida dos efetivos de população, e sua qualificação, que, por sua vez, criariam determinações quanto ao potencial de desenvolvimento dos diferentes espaços" (DAMIANI, 1991:57). A autora considera que "o fenômeno do povoamento não poderia ser compreendido sem as migrações" (DAMIANI, 1991:61). Assim, é preciso entender os tipos de migrações e os motivos que levam o migrante a tomar a decisão de se deslocar, sendo a questão econômica um dos principais fatores, pois a busca por emprego é um grande motivo que força os fluxos populacionais (SINGER, 1980).

Como já ressaltado anteriormente, em função do dinamismo econômico da capital paulista, os fluxos populacionais do país se concentraram especialmente em direção à cidade de São Paulo até a década de 1970. No entanto, a partir das décadas seguintes a crescente aglomeração industrial na metrópole de São Paulo e o aumento dos custos de produção passaram a acarretar decrés- 
cimo na lucratividade para certas empresas de determinados setores, especialmente o industrial, trazendo um processo de saturação na metrópole. Esse período também é marcado por formulação de políticas estatais, como as do governo federal através dos incentivos à desconcentração das atividades econômicas. Destaca-se, nessas inciativas, o caso do II PND (Plano Nacional de Desenvolvimento) que visava uma integração regional maior e um decréscimo nas disparidades. Segundo Lencioni (2004, p. 68), "essa diminuição relativa da indústria paulista, acompanhada da perda de posição da indústria do Rio de Janeiro são indicativos da desconcentração industrial do Sudeste, e da industrialização de outras áreas do território nacional "(...) A partir desse período, há investimentos em infra-estrutura que, principalmente para a periferia próxima da Região Metropolitana de São Paulo, possibilitam a migração de alguns ramos industriais. Esse processo de desconcentração na região metropolitana de São Paulo ocorre em função dos "custos de aglomeração". De acordo com Araújo (1999, p. 40) os fatores responsáveis por esse processo estão,

\footnotetext{
Expressos na saturação da infra-estrutura de transporte, na valorização imobiliária, nas restrições impostas pela legislação ambiental, etc. -, assim como fatores indutores do crescimento industrial no interior do estado - como os maciços investimentos estatais em infra-estrutura energética e de transportes, o crescimento da agroindústria da cana (Proálcool) e da laranja (voltado à exportação) - explicaram, em grande medida, o movimento de desconcentração econômica nas décadas de 70 e de 80 .
}

Retomando Lencioni (2004, p.71), essa transformação nas áreas industriais do estado de São Paulo contou com a ação estatal, e, como exemplo dessa forte participação do Estado em investimentos no interior paulista, temos a instalação das refinarias de petróleo em Paulínia e São José dos Campos, o desenvolvimento do Programa do Álcool, as indústrias de bens de capital que foram desencadeadas por esse programa, entre outros. Isso mostra a seletividade espacial que houve na desconcentração das indústrias na Região Sudeste, especialmente no estado de São Paulo cujos investimentos privilegiaram os espaços mais rentáveis. Conseqüentemente, com os avanços técnicos "as vantagens locacionais são fortalecidas e os lugares passam a ser cada vez mais diferenciados pelo seu conteúdo - recursos naturais, mão de obra, redes de transporte, energia ou telecomunicações" (DIAS, 1995, p.157).

Tais mudanças nas áreas industriais do país, em especial no estado de São Paulo, tiveram reflexos nos fluxos migratórios, pois os centros urbanos como as cidades do interior paulista que receberam muitas dessas indústrias que saíram da metrópole de São Paulo, também passaram a receber maior quantidade de pessoas vindas de diversos lugares do Brasil, ilustrando assim a influência econômica na dinâmica populacional do país.

Martine (2006) analisando os fluxos populacionais entre as Grandes Regiões a partir do final da década de 1980 (Tabela 1) percebe-se as alterações que ocorreram nas migrações inter-regionais. O que mais se destaca nos dados levantados pelo referido autor é o aumento na entrada de migrantes na região Nordeste nos três períodos analisados e uma queda na saída de pessoas no qüinqüênio 1999-2004. Também se destaca a região Sudeste que apresenta um decréscimo significativo na entrada de migrantes (aproximadamente 600 mil entre o primeiro e o último período analisados), e um aumento na saída de pessoas. Segundo Martine (2006) isso pode significar uma aparente ruptura do padrão histórico da migração inter-regional entre o Nordeste e o Sudeste, e, ao mesmo tempo, o fluxo de pessoas para o Nordeste, em parte, refere-se à migração de retorno. Isto é, observa-se a volta de muitos nordestinos para seus lugares de origem, os quais antes residiam principalmente na região Sudeste. 
Tabela 1 - Entradas e saídas de migrantes internos nas Grandes Regiões segundo informação da data fixa, 19861991, 1995-2000 e 1999-2004.

\begin{tabular}{|l|l|l|l|l|l|l|}
\hline & \multicolumn{3}{|c}{ Entradas } & \multicolumn{3}{c|}{ Saídas } \\
\cline { 2 - 7 } & $1986-1991$ & $1995-2000$ & $1999-2004$ & $1986-1991$ & $1995-2000$ & $1999-2004$ \\
\hline $\mathbf{N}$ & 408.522 & 355.438 & 330.660 & 277.298 & 292.747 & 266.919 \\
\hline NE & 477.907 & 647.375 & 848.002 & 1.354 .441 & 1.411 .423 & 934.589 \\
\hline SE & 1.426 .943 & 1.404 .871 & 844.677 & 786.815 & 946.284 & 1.059 .913 \\
\hline $\mathbf{S}$ & 285.270 & 330.614 & 305.063 & 470.641 & 349.814 & 270.477 \\
\hline CO & 627.287 & 625.244 & 534.879 & 336.734 & 363.274 & 331.383 \\
\hline Total & 3.225 .929 & 3.363 .542 & 2.863 .281 & 3.225 .929 & 3.363 .546 & 2.863 .281 \\
\hline
\end{tabular}

Fonte da tabela: Martine, $(2006, \text { p. } 350)^{3}$.

${ }^{3}$ Fontes: Dados para 1986-91 de Oliveira e Simões, 2004; dados para 1995-2000 e 19992004 obtidos de: IBGE, Censo Demográfico 2000 (a tabela não apresenta dados do qüinqüênio 1990-1994). Ainda segundo Martine (2006), apesar da PNAD se basear em dados amostrais, os resultados são representativos e indicam tendências, sugerindo possíveis pistas de análise.

4 Conforme Cavalcanti (1998, p. 29), "o referencial teórico das representações sociais surgiu na pesquisa como um recurso para a compreensão de concepções, idéias, conceitos e imagens sobre Geografia, que crianças e adolescentes vão formando na sua vida cotidiana, na qual se insere sua vida escolar". Ainda segundo essa autora, "o estudo das representações sociais tem, assim, como suporte a vida cotidiana e a atividade cognitiva dos sujeitos que as formam. Essa constatação permite a convicção de que 0 estudo do conteúdo das representações dos alunos sobre Geografia é um caminho para melhor conhecer o mundo vivido dos alunos, suas concepções e seu processo de construção de conhecimento" (CAVALCANTI, 1998, p. 32).

Geografia Ensino \& Pesquisa, v. 17, n.1 p. 147-160, jan./abr. 2013

Pesquisa-ação no estágio supervisionado: contribuições para o ensino de Geografia
Destacam-se ainda, nesse contexto, algumas alterações nos fluxos populacionais para as regiões com novas dinâmicas econômicas, como a Amazônia e os cerrados brasileiros, deslocamentos que estão comumente associados ao avanço da exploração mineral e madeireira e da fronteira agrícola. Esta última vem sendo responsável pela absorção de contingentes significativos de população de várias regiões do país. De acordo com a tabela acima, as regiões que apresentam essas novas áreas produtivas também apresentam um maior número de pessoas na entrada do que no fluxo de saída. Portanto, a distribuição da população pelo território brasileiro pode guardar relação com a espacialização das atividades econômicas, embora a questão econômica não seja o único fator que influencia na decisão de migrar.

\section{Em busca do entendimento do fenômeno a partir do histórico familiar dos alunos}

Partindo de um conhecimento prévio de que parte significativa da população residente nos bairros do entorno da escola em que foi realizado o estágio, no distrito de Nova Aparecida do município de Campinas/SP, é formada por migrantes de diversos lugares do país, propôs-se, dessa maneira, investigar as origens dos alunos e de seus familiares. Buscou-se identificar especialmente em que estado do Brasil eles nasceram, com o objetivo de facilitar o entendimento dos alunos sobre a relação entre a temática da migração e da industrialização brasileira, a partir do seu cotidiano. Paralelamente a esse objetivo, adicionamos na discussão com os alunos às questões relativas às transformações socioeconômicas e espaciais do país durante o século XX e, em especial, às ocorridas nas últimas décadas.

Para tanto, inicialmente foi elaborado um projeto de atividade prática, executado na disciplina Estágio Supervisionado de Geografia II, para ser desenvolvido numa entidade escolar. O plano de trabalho realizado ao longo de um semestre foi organizado a partir do tema "Migração interna, concentração industrial no Brasil e desconcentração das indústrias na metrópole de São Paulo pós1970 " tendo como base do projeto as representações sociais ${ }^{4}$ dos alunos que, segundo Moscovici (2010, p. 54), têm como finalidade "tornar familiar algo não familiar, ou a própria não familiaridade".

Os principais objetivos do trabalho foram: apresentar uma periodização dos fluxos migratórios internos identificando as regiões de origem dos maiores fluxos e seus principais destinos; analisar a origem e a conformação das indústrias no território nacional; discutir o processo de desconcentração industrial na metrópole paulista e a sua relação com as cidades próximas a RMSP e contribuir para o entendimento da relação entre esses processos. A metodologia utilizada no trabalho foi: aulas expositivas, leitura e interpretação de texto, produção de gráficos, localização em mapas do Brasil.

Como recursos didáticos foram utilizados gráficos, mapas temáticos, imagens, data show, questionário, etc. Foi proposto também um trabalho de campo que consistiria numa visita a uma 
fábrica de algum produto utilizado pelos alunos em seu cotidiano para compreender melhor as informações sobre a localização das indústrias e também levantar dados sobre alguns trabalhadores dessa fábrica, se eles (os trabalhadores) moravam em outro município, para que os alunos pudessem entender melhor o conceito de uma das variáveis da migração, isto é, a diária ou pendular ${ }^{5}$. Por fim, as avaliações foram realizadas através de provas e participações dos alunos nas atividades propostas ao longo do semestre. Segundo Callai (2000), o professor "é o responsável pelo planejamento e desenvolvimento das atividades, criando condições para que se efetive a aprendizagem por parte do aluno. Sem que exista um consistente planejamento fica difícil dar conta da tarefa", (CALLAI, 2000, p. 93).

\section{Discussão teórica e formação de conceitos geográficos}

Antes de trabalhar a temática proposta no projeto de estágio, foram trabalhados pela professora da turma na escola, os seguintes temas: formação do território brasileiro; localização do Brasil: continentes, fronteiras, etc.; regionalização do território nacional; conceitos sobre migração (externa, interna, emigração, imigração, inter e intra-regional, definitiva, pendular, etc.); População Economicamente Ativa e Inativa (PEA e PEI). Também foram trabalhadas as noções de escala, os elementos que devem estar presentes em um mapa como: legenda, escala, título, etc., assim como os elementos que compõem um gráfico, reconhecendo que a representação gráfica é um importante instrumento para o desvendamento das dinâmicas espaciais. Conforme Castrogiovanni (2000, p. 37), "as maquetes, mapas, cartas e plantas são representações sociais de um determinado espaço real e representam uma organização dos elementos que compõem o espaço".

Assim, o trabalho desenvolvido anteriormente contribuiu para a compreensão dos alunos sobre a temática trabalhada nas aulas expositivas no decorrer do estágio. Essas aulas foram ministradas a partir da leitura de um texto sobre os aspectos históricos sócio-econômicos e espaciais dos processos de industrialização no Brasil e a sua relação com a migração interna no país, partindo de uma pequena periodização desses processos. Segundo Castrogiovanni, (2000, p. 65),

\footnotetext{
A análise do processo de formação histórica do espaço geográfico é que possibilita interpretações na busca de seu entendimento. Embora devamos também conhecer a forma, a função e as estruturas que envolvem o espaço, para que possamos entendê-lo nas suas grandiosidades interativas, faz-se necessário a análise contínua do seu processo de formação, ou seja, os seus movimentos históricos.
}

Também foi apresentada nessas aulas expositivas uma série de slides com mapas temáticos, imagens e gráficos, os quais ilustravam a relação entre o processo de concentração industrial no Brasil e os fluxos migratórios. Além disso, foram discutidos os outros processos associados, tais como, a formação dos maiores centros urbanos brasileiros e a concentração populacional no território nacional.

\section{A construção do conhecimento em sala de aula: a aliança entre a teoria e a prática}

Após a abordagem da temática a partir da análise dos conceitos geográficos, partiu-se para o desenvolvimento das atividades práticas. Nessa etapa, foi aplicado um questionário aos alunos, para ser respondido em casa com a participação dos pais ou responsáveis, abordando as seguintes perguntas: 1) Em qual estado do Brasil você nasceu?; 2) Quantos anos você tem?; 3) Em qual estado do Brasil seus pais ou responsáveis nasceram? (pai ou responsável, mãe ou responsável); 4) Até que série seus pais ou responsáveis estudaram? (pai ou responsável, mãe ou responsável); 5) Em qual bairro você mora?

A partir dos questionários respondidos, foi solicitado aos alunos que localizassem em um mapa do Brasil (com as divisões administrativas regionais e estaduais) o estado em que seus pais
${ }^{5}$ Não foi possivel realizar 0 trabalho de campo

Geografia Ensino \& Pesquisa, v. 17, n.1 p. 147-160, jan./abr. 2013

Santos, S. A.; Alves, V. E. L. 
nasceram. Cada aluno localizou no mapa o estado em que o seu pai e a sua mãe nasceram e posteriormente todos os mapas foram colados, um ao lado do outro, para possibilitar uma melhor visualização das regiões onde apresentavam maior número de estados "coloridos". Como resultado, produzimos a imagem abaixo (figura 1).

Figura 1 - Localização dos estados em que os pais ou responsáveis dos alunos nasceram.

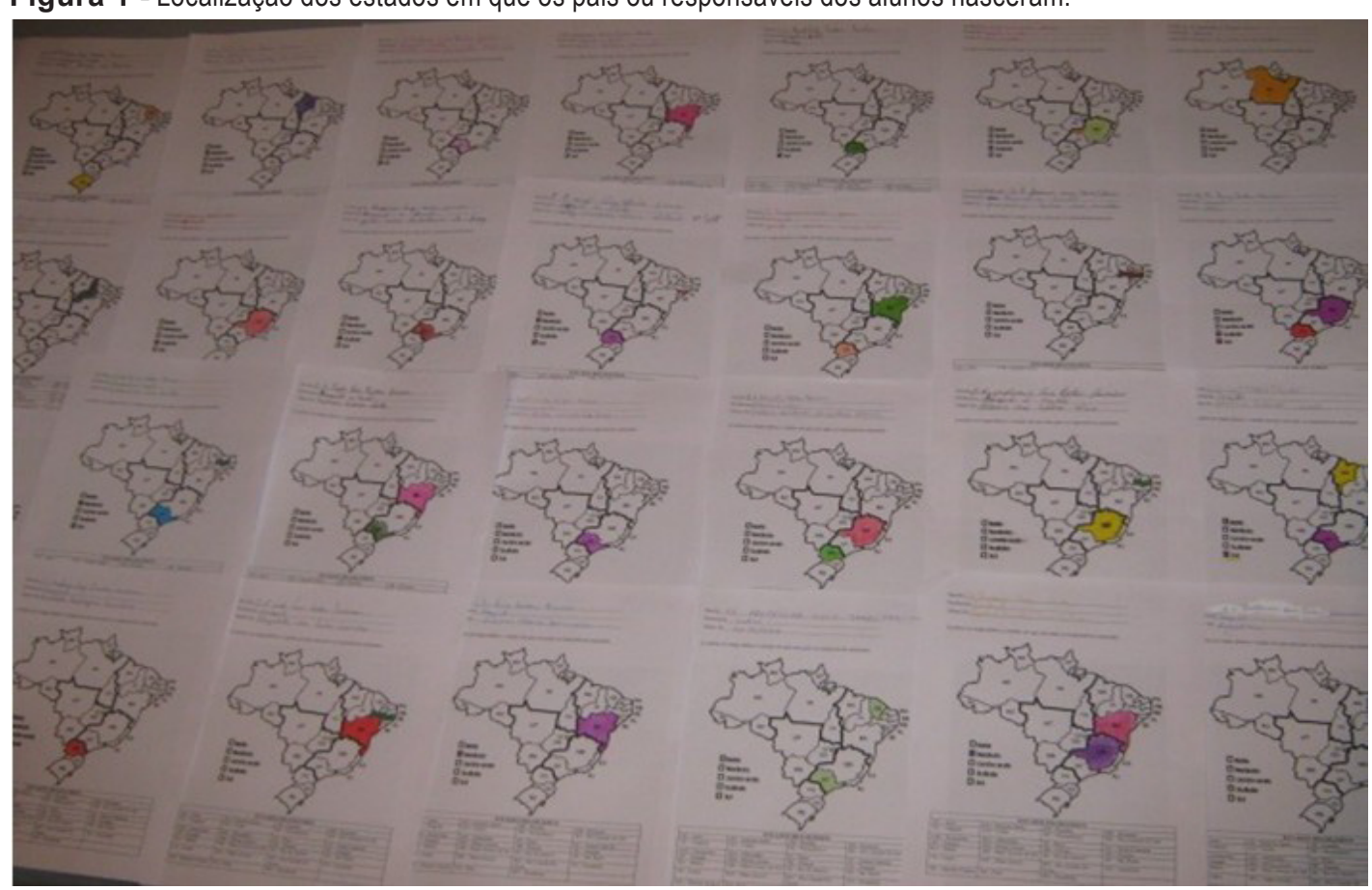

Fonte: Elaboração própria a partir da localização dos estados de origem dos pais realizada pelos alunos.

Depois de tabulados os dados do questionário aplicado anteriormente, propôs-se aos alunos a produção de gráficos no software Excel na sala de informática da escola. Primeiramente mostramos aos alunos como se produz um gráfico, quais informações devem conter nesse tipo de representação e, na sequência, os dados levantados através do questionário foram fornecidos aos alunos para que eles próprios (dois alunos por computador) produzissem os gráficos. Os alunos se mostraram muito interessados no desenvolvimento dessa atividade e a maioria não apresentou dificuldade no manuseamento dos programas de computador e na elaboração do material solicitado. "Softwares educativos também podem ser um importante recurso no aprendizado do educando, pois trazem acoplados ao conteúdo, imagens ilustrativas que aguçam a curiosidade e a vontade de aprender dos alunos" (BOTELHO; ANTONELLO, 2005, p. 91). Segundo Moura (2005, p. 166), "0 professor de hoje não deve dispensar as novas tecnologias, como o uso de computadores no ensino, pois entende-se que este é um instrumento facilitador para 0 aluno e equipamento necessário às exigências do mundo moderno".

Os gráficos foram produzidos (conforme figuras 2, 3, 4, 5 e 6) e, na sequência, foram apresentados a toda classe através do uso do programa PowerPoint. Realizou-se, posteriormente, uma análise e discussão dos resultados relacionando-os com o processo de industrialização e os fluxos populacionais, reforçando os conceitos já trabalhados, a partir de exemplos dos alunos e das suas famílias. Assim, evitou-se que o trabalho em sala de aula ficasse apenas nas atividades lúdicas, mas que proporcionasse oportunidades de avanço do conhecimento, pois conforme Gulart (2011, p. 21),

Pesquisa-ação no estágio supervisionado: contribuições para o ensino de Geografia

Para efetivar uma aprendizagem geográfica, é fundamental que as temáticas tenham sentido para os alunos, que haja clareza de objetivos por parte do professor e que o trabalho seja orientado buscando a formação cidadã. As atividades precisam ser interessantes e lúdicas, mas sua finalidade não pode se esgotar aí. As possibilidades de um trabalho significativo estão ligadas às questões de envolvimento e mobilização dos alunos, mas a isso precisa estar associado o trabalho intencional que inclua a apreensão de conteúdos e habilidades que favoreçam as conexões. 
Figura 2 - Local de nascimento dos pais dos alunos da $6^{a}$ série.

Total de pais nascidos por Região Político-Administrativa do Brasil

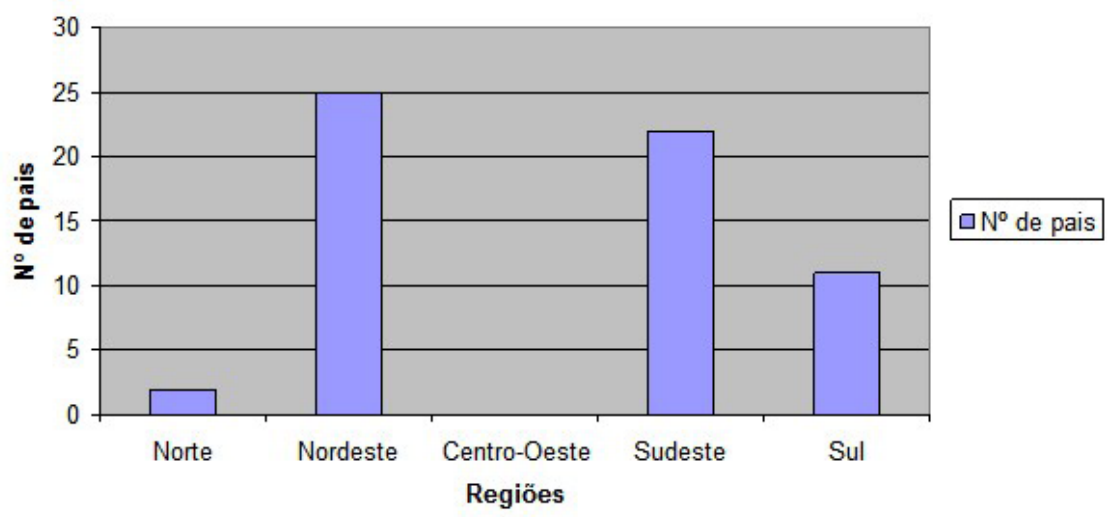

Fonte: Elaboração própria a partir dos questionários respondidos pelos alunos.

Figura 3 - Local de nascimento dos alunos da $6^{\text {a }}$ série

Total de alunos nascidos por Regiäo Político-Adminis trativa do Brasil

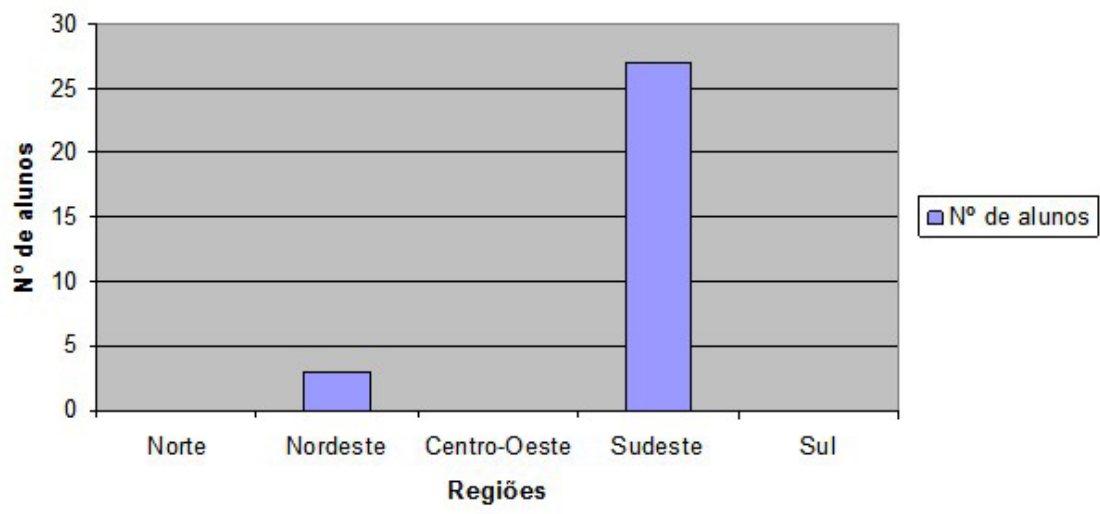

Fonte: Elaboração própria a partir dos questionários respondidos pelos alunos.

Figura 4 - Local de nascimento dos pais dos alunos, por estados e regiões

Total de pais nascidos por estados do Sudeste e nas quatro regiões brasileiras

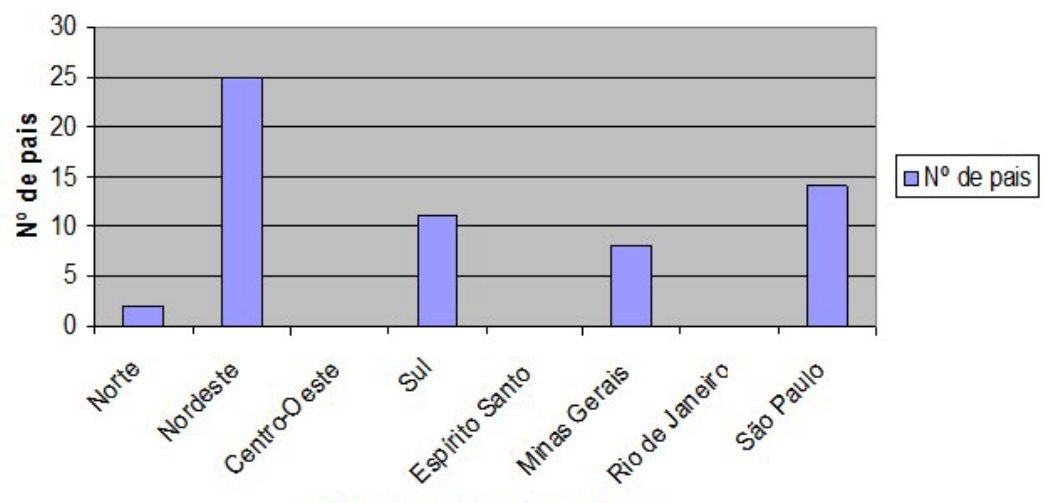

local de nascimento dos pais

Fonte: Elaboração própria a partir dos questionários respondidos pelos alunos.

Geografia Ensino \& Pesquisa, v. 17, n.1 p. 147-160, jan./abr. 2013

Santos, S. A.; Alves, V. E. L. 
Figura 5 - Local de nascimento dos alunos, por Estados e regiões

Total de alunos nascidos por estados do Sudeste e nas quatro regiões brasileiras

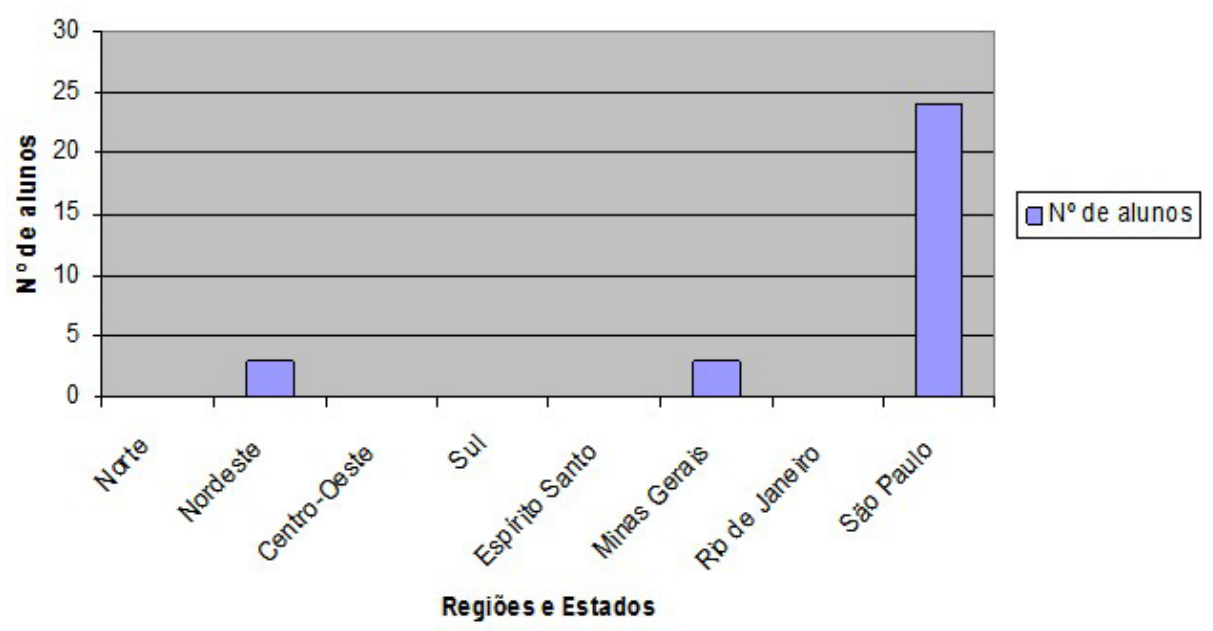

Fonte: Elaboração própria a partir dos questionários respondidos pelos alunos.

${ }^{6}$ Migração permanente ocorre quando os indivíduos decidem ficar definitivamente no local para onde migraram. A migração tende a ser definitiva, pois, quanto maior o tempo de residência, maiores serão as possibilidades de assimilação da cultura local e da incorporação ao mercado de trabalho. No entanto, para Martins (1988, p. 49) mesmo quando a migração é considerada definitiva em termos demográficos, no aspecto sociológico ela ainda pode ser temporária em função da concepção de ausência do migrante, pois se "a ausência é o núcleo da consciência do migrante temporário, é porque ele não cumpriu e não encerrou 0 processo de migração, com seus dois momentos extremos e excludentes: a dessocialização, nas relações sociais de origem, e a ressocialização, nas relações sociais de 'adoção'" (MARTINS, 1989, p. 50)

Geografia Ensino \& Pesquisa, v. 17, n.1 p. 147-160, jan./abr. 2013

Pesquisa-ação no estágio supervisionado: contribuições para o ensino de Geografia
Vale ressaltar que para a discussão sobre os resultados apresentados nos gráficos acima, foi realizado, num pequeno texto em sala de aula, uma breve periodização do processo de industrialização brasileira, o surgimento das primeiras indústrias, o processo de industrialização pesada com a implantação de infraestrutura necessária à instalação dessas indústrias. Buscou-se, sobretudo, relacionar essas questões com os fluxos migratórios que ocorreram nesse período e, finalmente, o processo de desconcentração industrial na metrópole paulista e a interiorização de muitas indústrias, com destaque para as cidades como Campinas e São José dos Campos. Isso foi importante na medida em que possibilitou explicar aos alunos os motivos pelos quais muitos migrantes passaram a buscar essas cidades - inclusive muitos dos seus pais $(75 \%)$ nasceram em outros estados e migraram para São Paulo, enquanto que $80 \%$ dos alunos já nasceram no referido estado. (figuras 2 e 4). A partir dessa informação sobre a diferença do local de origem dos pais em relação aos alunos, chamamos a atenção deles para o fato de que tal situação pode se tratar de um exemplo de migração permanente ${ }^{6}$ uma vez que a maioria deles já nasceu no estado de São Paulo. Ao contrário dos pais, que é a maior parte composta de migrante. Essa foi uma das questões que procuramos levantar em sala de aula para mostrar ao aluno como ele está inserido em processos como estes, de dimensão nacional. Cavalcanti, (2011, p. 87), considera que,

para que os alunos entendam os espaços de sua vida cotidiana, que se tornaram extremamente complexos, é necessário Ihes propiciar uma Geografia estruturada de tal modo que dê conta de levá-lo a analisar, ao mesmo tempo, um contexto mais amplo e global, do qual todos formam parte, e os elementos que caracterizam e distinguem seu contexto local, onde realiza sua vida individual cotidiana.

Além da discussão a respeito da mudança do local de origem dos pais em relação aos alunos, refletindo sobre a alteração na dinâmica populacional que ocorreu nas últimas décadas no país e que foi possível perceber através dessa microescala analisada - o histórico familiar de uma turma de alunos -, também analisamos outra característica muito presente entre a geração de migrante nas décadas passadas, isto é, a baixa escolaridade. Procuramos mostrar aos alunos em relação a essa questão que a baixa escolaridade de seus pais estava associada às condições socioeconômicas pelas quais eles passaram em um momento em que o Brasil acabava de entrar num contexto de urbanização. Mostramos que os seus pais tiveram menos oportunidade de estudar porque, provavelmente, muitos deles vieram de realidades agrárias e que 0 acesso à escola 
naquele momento era dificultado, especialmente para aqueles que habitavam as áreas rurais. Isso pode ser observado no gráfico abaixo (Figura 3), o qual mostra que a maioria dos pais não concluiu o ensino médio, sendo que apenas um pai e uma mãe concluíram o ensino superior.

Figura 6 - Grau de escolaridade dos pais dos alunos

\section{Nivel de escolaridade dos pais}

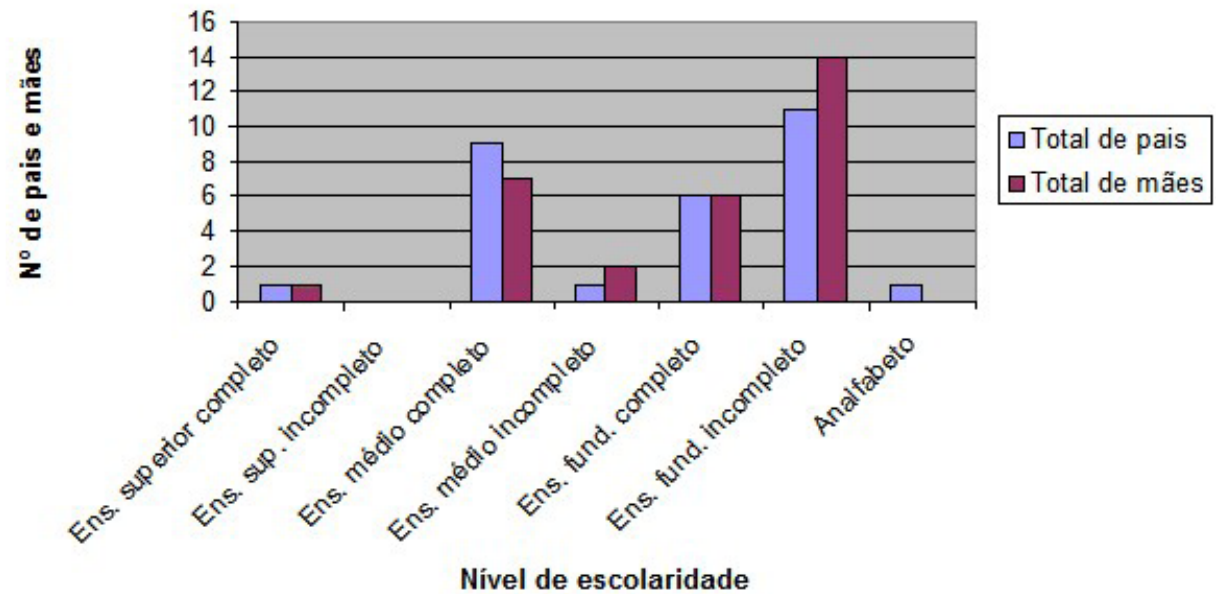

Fonte: Elaboração própria a partir dos questionários respondidos pelos alunos

Com isso, foi possivel tratar de maneira integrada a questão do êxodo rural, a industrialização e a formação das grandes cidades, temáticas importantes para o entendimento do contexto social vivido pelo aluno.

A geografia escolar para dar conta do seu objeto do estudo, que é o espaço geográfico, segundo Castrogiovanni (2000, p. 7), "deve lidar com as representações da vida dos alunos, sendo necessário sobrepor o conhecimento do cotidiano aos conteúdos escolares, sem distanciar-se, em demasia, do formalismo teórico da ciência". Portanto, através das discussões teóricas e das atividades práticas desenvolvidas ao longo de um semestre de estágio, procuramos contribuir para a construção dos conceitos geográficos partindo do cotidiano do aluno, com o objetivo de facilitar a sua compreensão sobre alguns fenômenos extremamente importantes na organização espacial de um país, como é o caso da distribuição das indústrias pelo território brasileiro e, consequentemente, da influência desse processo na dinâmica populacional. Além disso, tentamos mostrar aos alunos de que maneira processos amplos como o da industrialização brasileira e da migração interna fazem parte do seu cotidiano e que, portanto, eles (os alunos) também são sujeitos dessa história.

\section{Considerações finais}

A análise das representações sociais dos alunos permitiu, em primeiro lugar, conhecer meIhor a turma através da idade, bairro onde mora etc., também proporcionou maior conhecimento aos alunos sobre o seu histórico familiar, como exemplo, o local onde os pais nasceram e o grau de escolaridade, pois ao entregar-Ihes o questionário, alguns alunos afirmaram não saber responder em sala de aula, daí foi explicado que o questionário era para ser respondido em suas casas, com a ajuda dos pais. Além disso, trouxe elementos para a compreensão dos alunos através da atividade de levantamento de dados a partir de um questionário, tabulação de dados, produção de gráficos, análise dos resultados, etc., foi exemplificado como ocorre o processo de uma pesquisa, na qual os alunos podem ver os resultados em gráficos, tabelas e/ou mapas, semelhantes aos existentes em seus livros didáticos.

Geografia Ensino \& Pesquisa, v. 17, n.1 p. 147-160, jan./abr. 2013

Santos, S. A.; Alves, V. E. L. 
A junção do conhecimento cotidiano (as representações sociais) e do conhecimento científico é importante no processo de ensino/aprendizagem, pois ajuda a entender melhor os temas que fazem parte do saber geográfico escolar e que segundo Gulart (2011, p. 19),

Há, por parte dos professores de Geografia, uma busca incessante ao explicar que a Geografia não se refere a informações e dados, e que esses, isolados, pouco representam para a compreensão do mundo em que vivemos. Esse campo do conhecimento está preocupado com questões vinculadas à espacialidade, e não às informações enciclopédicas. Mesmo que muito se tenha dito desde a antiguidade sobre o papel estratégico dos conhecimentos geográficos, a sociedade continua com a concepção distorcida daquilo que é a Geografia, isto é, nomes de lugares, dados estatísticos e localização de diferentes pontos no globo.

A partir dessa experiência vivida em sala de aula, numa escola pública com cerca de trinta e cinco alunos na turma, foi possível perceber que, apesar das dificuldades enfrentadas pelos professores em relação às condições de trabalho, ainda há possibilidade de desenvolver estratégias de ensino que tenham bons resultados. Mas, para isso, é necessário o empenho e o compromisso maiores dos agentes envolvidos nesse processo de ensino/aprendizagem. Por outro lado, não podemos correr o risco de atribuir às responsabilidades pelos problemas da educação básica, especialmente a pública, apenas à entidade escolar e ao seu corpo docente, na medida em que estes ainda cumprem um importante papel no processo de transformação da sociedade moderna. Nessa mesma direção as disciplinas ministradas aos educandos devem assumir também o seu papel transformador, como é o caso da Geografia, pois segundo Moura, (2005, p. 164),

\footnotetext{
Acredita-se que a Geografia pode contribuir com a transformação de sujeitos sociais, levando-os a refletirem sobre os elementos responsáveis pelas diferentes territorialidades, no entanto não se pode ter uma visão romântica de que a Geografia, aliada às demais disciplinas do currículo escolar, pode promover uma transformação na sociedade, pois esta depende de processos muito mais amplos, mas entende-se que a educação aponta para um dos caminhos para a democratização social.
}

Portanto, considera-se que a escola através da relação professor/aluno é um dos subsídios para que os sujeitos sociais adquiram uma visão de mundo capaz de contribuir de forma coletiva para a transformação social, minimizando, assim, a visão hegemônica do atual período histórico que valoriza o sujeito individualista e consumista. A escola possui, nesse sentido, um papel preponderante na formação de pessoas mais solidárias e críticas. Para tanto, é necessário proporcionar aos educandos a possibilidade de conhecer a sua própria história de vida. Somente dessa maneira é que podemos formar indivíduos verdadeiramente transformadores. A escola e, em particular, a Geografia podem contribuir nessa direção.

\section{Referências bibliográficas}

ARAÚJO, Maria de Fátima Infante. Mapa da estrutura industrial e comercial do Estado de São Paulo. São Paulo em perspectiva. Fundação Seade, vol. 13, n 1-2, jan-jun, p.40-52, 1999.

Geografia Ensino \& Pesquisa, v. 17, n.1 p. 147-160, jan./abr. 2013

Pesquisa-ação no estágio supervisionado: contribuições para o ensino de Geografia
BECKER, Bertha Koiffmann. Geopolítica da Amazônia: A nova fronteira de recursos. Editora Zahar Editores, Rio de Janeiro, 1982.

BOTOELHO, Jean Cleverson Novais; ANTONELLO, Ideni Terezinha. Os computadores como ferramenta de ensino para a geografia. In: ANOTONELO, Ideni Terezinha et al. (Orgs.). Múltiplas Geografias: Ensino-Pesquisa-Reflexão, vol II. Londrina: Humanidades, 2005, p 87-103 
CALLAI, Helena Copetti. Estudar o lugar para compreender o mundo. In: CASTROGIOVANNI, Antônio Carlos. (Org.) Ensino de geografia: práticas e textualizações no cotidiano. Porto Alegre: Mediação, 2000. 173p.

CANO, Wilson. Desequilíbrios regionais e concentração industrial no Brasil, 1930-1995. $3^{\mathrm{a}}$ ed. - São Paulo: Editora UNESP, 2007. Cap. 3 - Movimento da indústria e sua concentração regional (1930-1970), p. 71-119.

CASTROGIOVANNI, Antônio Carlos. Apreensão e compreensão do espaço geográfico. In: CASTROGIOVANNI, Antônio Carlos. (Org.) Ensino de geografia: práticas e textualizações no cotidiano. Porto Alegre: Mediação, 2000.173p.

Ensino de geografia: práticas e textualizações no cotidiano. Apresentação. Porto Alegre: Mediação, 2000. 173p.

CAVALCANTI, Lana de Souza. A geografia escolar e a sociedade brasileira contemporânea. In: TONINI, Ivaine Maria et al. (Orgs.) Ensino de geografia e suas composições curriculares. Porto Alegre: UFRGS, 2011.

Geografia, escola e construção de conhecimentos. Campinas, SP: Papirus, 1998. -(Coleção Magistério: Formação e Trabalho Pedagógico).

DAMIANI, Amélia Luisa. População e Geografia. São Paulo, Contexto, 1991.

DIAS, Leila Christina. Redes: emergência e organização. In: CASTRO, Iná Elias et al. (orgs.), Geografia: conceitos e temas. Rio de Janeiro: Bertrand Brasil, 1995, p.141-162.

GOULART, Lígia. Beatriz, Aprendizagem e ensino: uma aproximação necessária à aula de geografia. In: TONINI, Ivaine Maria et al. (orgs.) Ensino de geografia e suas composições curriculares. Porto Alegre: UFRGS, 2011.

HAKKERT, Ralph; MARTINE, George. Tendências migratórias recentes no Brasil: as evidências da PNAD de 2004. Parcerias Estratégicas, Ed. Especial, n.22, Jun. 2006.

LENCIONI, Sandra. Novos rumos e tendências da urbanização e a industrialização no Estado de São Paulo. In: LIMONAD, Esther et al. (Orgs.) Brasil, Século XXI - por uma nova regionalização? Processos escalas, agentes/organizadores: São Paulo: Max Limonad, 2004.

MARTINE, George. A evolução espacial da população brasileira. In: AFFONSO, Rui de Britto Álvares; SILVA, Pedro Luiz Barros (orgs.) Desigualdades regionais e desenvolvimento. São Paulo: FUNDAP: Editora da Universidade Estadual Paulista, 1995.

A natureza e os impactos das políticas públicas sobre a distribuição espacial da população no Brasil. São Paulo em Perspectiva, 3(3):46-56, Jul./Set. 1989.

MARTINS, José de Sousa. Não há terra para plantar neste verão ( 0 cerco das terras indígenas e das terras de trabalho no renascimento político do campo). Cap. II - O vôo das andorinhas: migrações temporárias no Brasil, p. 43-61. Petrópolis: Vozes, 1988.

MOSCOVICl, Serge. Representações sociais: investigações em psicologia social. Editado em inglês por Gerard Duveen; traduzido do inglês por Pedrinho A. Guareschi. 7. ed. - Petrópolis, RJ: Vozes, 2010.

Geografia Ensino \& Pesquisa, v. 17, n.1 p. 147-160, jan./abr. 2013 
MOURA, Jeani Delgado Paschoal; ASARI, Alice Yatiyo. Uso de computadores no ensino de geografia. In: ANTONELLO, Ideni Terezinha et al. (orgs.) Múltiplas geografias: ensino - pesquisa - reflexão. Londrina - PR. Edições Humanidades, 2005.

SINGER, Paul, Migrações internas: considerações teóricas sobre o seu estudo. In Migração Interna. Textos Selecionados, tomo I, coordenador, MOURA, Hélio. Fortaleza: Banco do Nordeste, 1980.

\section{Correspondência:}

Sueli Almeida dos Santos- Rua João Pandiá Calógeras, 100 - GEOPLAN - Laboratório de Investigações Geográficas e Planejamento Territorial. CEP. 13083-970 - Campinas, SP

E-mail:salmmeida@yahoo.com.br

Recebido em 28 de março de 2012.

Aceito para publicação em 17 de janeiro de 2013. 